A $R$ R T I I C C U L L O O D

$\begin{array}{lllllllll}R & E & F & L & E & X & I & O & N\end{array}$

\section{¿QUÉ PASADO NARRAR EN LA EDUCACIÓN? GESTOS DESCOLONIALES EN LA HISTORIA DEL BACHILLERATO ARGENTINO}

\author{
WHICH PAST SHOULD EDUCATION NARRATE? \\ DECOLONIAL GESTURES IN THE HISTORY OF THE ARGENTINE HIGH \\ SCHOOL
}

Por: Francisco Ramallo*

* Docente e investigador del Departamento de Ciencias de la Educación y del Centro de Investigaciones Multidisciplinares en Educación, Facultad de Humanidades Universidad Nacional de Mar del Plata Becario del Consejo Nacional del Contigaciones Científicas tigaciones Científicas y doctor en Humanidades y Artes con mención en Ciencias de la Educación (Universidad $\mathrm{Na}$ cional de Rosario)

Recibido: 2 de junio de 2017 - Aprobado: 21 de mayo de 2018

\section{RESUMEN}

Este artículo rastrea una conversación entre las formas de componer la historia de la educación y las trasgresiones que podrían enunciarse desde las perspectivas descoloniales. En un primer momento destacamos una narrativa genealógica de estas perspectivas en la educación que convoca a recuperar nuestro propio paisaje colonial, desde la (des)composición de "el" relato universal. En un segundo momento los relatos del bachillerato argentino de la segunda mitad del siglo XX son interpelados a partir de los hallazgos de nuestra investigación doctoral que propone abandonar una enunciación nostálgica, a la vez que abraza una narración utópica de los pasados en la educación. Finalmente esta preocupación rescata la necesidad de reconocer gestos oportunos para significar otros hilos de sentidos capaces de intervenir el relato colonial de la educación que habitamos cotidianamente.

Palabras clave: Educación, Perspectiva descolonial, Investigación narrativa, Memoria.

\begin{abstract}
This article deals with a conversation between the standard ways of composing the history of education and the transgressions that decolonial perspectives propose. We begin by drawing a genealogical narrative of such perspectives, which intends to recover our own particular colonial landscape as we (de)compose "the" universal tale. Then, the stories of Argentine high schools of the second half of the 20th century are analyzed under the scope of Doctoral research work which has proposed to abandon a nostalgic stance and embrace a utopic narrative of the pasts of education. Finally, we highlight the need to recognize timely gestures that may contribute to the intervention of the colonial tale that we daily inhabit.
\end{abstract}

Keywords: Education; Decolonization perspective, Narrative Inquiry; Memory

\section{Introducción}

a Historia de la Educación durante mucho tiempo se escribió
presentándole poca atención a una reflexión ontológica, epistémica,
política y pedagógica de sus relatos. Entresus diferentes estilos y diversas 
tradiciones, el modo de relatar las historias en la educación se ubica en medio de un debate que también suele caracterizar al desarrollo de la historia como ciencia y aún más ampliamente a los modos de recordar colectivamente nuestros pasados. Podríamos contraponer diversas perspectivas en un enorme arco, que recorre desde las posturas que asumen el análisis histórico como la reconstrucción de los hechos (a través de un riguroso trabajo con fuentes documentales) hasta aquellas que se concentran en el estudio de los procesos históricos y construyen los significados que estos tuvieron para los sujetos, entendiendo a la historia como transformación del significado de lo vivido. Más aún este arco es expandido por otras perspectivas cuya pretensión es reconstruir el sentido y el para qué de las historias en la pedagogía actual.

En tanto que múltiples son las formas de analizar y comprender estos relatos, en nuestra investigación sobre los modos de narrar las historias del bachillerato argentino recogimos una perspectiva narrativa promotora de entramar una dimensión desde la diferencia cultural y local, que perturbó a la gloria de los colegios nacionales desde una narración utópica Ramallo, (2017). Asimismo procuramos corrernos de una perspectiva de la Historia de la Educación desde arriba, normativa y tecnocrática; que pueda ir un poco más allá, dejando atrás su mirada sistémica y totalizante que olvida lo más sensible y transformador: las prácticas y los gestos cotidianos de los sujetos tanto dentro como fuera de las aulas.

Para ello advertimos que la Historia (con mayúscula), suele deslegitimar y anular lo vivido, en una representación del pasado (siempre subjetiva e incompleta) que se erige objetiva, retrospectiva y justificada en la distancia. Contrariamente en nuestro abordaje resaltamos un pasado vivido eimaginado, afectivo y emotivo, abierto a sucesivas transformaciones y susceptible de permanecer latente durante largos períodos como de bruscos despertares. En efecto advertimos que los relatos sobre el bachillerato argentino, pese a la desaparición de los colegios nacionales tienen ecos en el presente, están vivos en los viejos pasillos de las nuevas escuelas, en las memorias y en las experiencias de los sujetos que los transitan. En tanto que resuenan y sedimentan el presente, alimentan posicionamientos y constituyen modelos desde donde educar a los jóvenes de nuestro siglo.

A partir de las perspectivas descoloniales comprendimos que una narrativa de este tipo no puede ser valorada únicamente en función de sus procedimientos, sino en virtud de los fines a los que se orienta y los modos 
1 Especialmente las reformas constitucionales y las políticas públicas de reconocimiento del "buen vivir", en oposición a la noción de progreso y de desarrollo eurocentrado despertaron la atención sobre la "colonización pedagógica" de las normativas escolares, sobre todo en países con fuertes reafirmaciones de pueblos indígenas y afrodescendientes en sus reglamentos jurídicos Pero así también otras más cercanas como los diseños curriculares para la enseñanza de la historia en el contexto bonarense (en el marco de la Nueva Escuela Secundaria Argentina). Al respecto del contexto local puede consultarse el texto de Huergo, J. y Morawicki,K. (2010). "Una reescritura contrahegemónica de la formación de docentes" En: Revista Nómadas N33, Universidad Central de Colombia, octubre de 2010 y Ramallo, Francisco (2016). África en Argentina: Pedagogías descoloniales y enseñanza de la historia. Tesis de maestría en estudios étnicos y africanos. Salvador Universidad Federal de Bahía. como su hacer construye o aniquila las posibilidades políticas en las personas Yedaide, Álvarez y Porta, (2015). En la comunidad académica local, el Grupo de Investigadores en Educación y Estudios Culturales de la Universidad Nacional de Mar del Plata, profundizamos la idea de que una investigación narrativa no solo implica una metodología específica -como podría ser el enfoque biográfico-narrativo-, sino que además constituye otro modo de conocer. Una forma que es eminentemente política, que invierte la ecuación y remarca que la investigación es un tipo de narrativa. De modo tal que la narrativa no tiene solo un uso técnico, sino también uno ontológico, epistémico, político y pedagógico. En gran medida es una práctica subversiva que coloca una pregunta donde las formas convencionales de construcción de saberes no esperan ser interpeladas.

En este recorrido es que las perspectivas descoloniales atravesaron nuestra investigación y la ubicaron en la disputa acerca del sentido de lo que es investigar y lo que puede y debe esperarse de esta empresa. Desde estas perspectivas la ciencia clásica queda cartografiada en un mapa más abarcador de las formas de colonización que nos conforman hasta nuestros días, habitando nuestros cuerpos y mentes. Las perspectivas descoloniales con coordenadas geográfico-temporales precisas y campos académicos-culturales diversos, proponen una analítica del pasado y una proyección hacia el futuro que confirman una práctica productora de saberes transitorios, que van constituyendo un territorio habitado para una educación emancipadora. Son perspectivas con cuerpos, espacios y tiempos, que se deben a la irremediable inmediatez de las experiencias concretas de los sujetos inscriptos en gramáticas de sufrimientos Porta y Yedaide, (2017).

\section{Las perspectivas descoloniales en la educación}

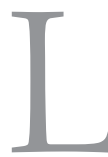

as perspectivas descoloniales en la educación, aunque no son recientes, son novedosas en su poderosa insurgencia en las academias de nuestra trabajo científico construida no solo desde "adentro/afuera" sino también más allá de dichos límites, aludiendo a la instalación de relatos que buscan romper con el binomio de pensamiento impuesto por la dominación occidental y colonial. En los últimos años tanto dentro de las ciencias sociales y las humanidades como desde el escenario de las políticas educativas latinoamericanas (con la aparición de nuevas leyes y marcos educativos) es posible advertir - aunque sumamente variada y aún poco articulada- una tendencia o una agenda preocupada por la descolonizar la educación.1 Esta 
conversación continental y del sur global implica un esfuerzo por incoporar otros saberes al conocimiento eurocentrado y occidentalizado. A partir de la perspectiva de la colonialidad del poder iniciada por Anibal Quijano, se sedimentó una discusión académica que rechaza la imposición de la cultura europea como cultura universal, en el desenmascarar de la "hybris del punto cero" Castro Gómez, (2005) que ubica a lo occidental por encima de otras lógicas, otras razones, otras formas de ser y estar en el mundo.

A su vez estos posicionamientos surgieron como herederos directos de una serie de tradiciones tanto del campo académico y pedagógico como cultural y político. Lo descolonial conjuga la expresión latinoamericana con las teorías del sur y otros marcos epistemológicos de contextos africanos, del sudeste asiático y otras periferias en los centros globales del poder. Si bien esta disposición hacia el giro descolonial se despierta en nuestra comunidad a través del Programa Modernidad/Colonialidad y el alcance de estos pensadores en el círculo académico intelectual latinoamericano, nuestra elección del prefijo des supone una toma de postura a la vez agradecida e irreverente.

Asimismo las perspectivas descoloniales se componen en la vida misma y en las luchas por la dignidad humana. Tal como resaltó Walter Mignolo (2007) provienen y se enfrentan desde el mismo momento de la colonización en los movimientos de combate por la vida de los pueblos y las culturas oprimidas del sur, podríamos decir que se inician a partir de la (re)identificación de las gentes con sus dignidades, sus historias y sus vidas. Entonces recuperan diferentes tradiciones y experiencias tanto lejanas como cercanas en el tiempo que se deslizan en variados espacios del sur (o de los sures), como manera de enunciar la experiencia biográfica, histórica, geopolítca y geocultural que se desprende de los pueblos y culturas oprimidas por el norte global.

En la educación estas perspectivas pueden rastrearse en las marcas por el (re) existir, el (re)vivir y el (in)surgir. Explicó Caterinhe Walsh $(2013 ; 26)$ que lo pedagógico y lo descolonial adquieren su razón y su sentido político, social, cultural y existencial como apuestas accionales fuertemente arraigadas en la vida misma y por lo tanto a las memorias colectivas que los pueblos han venido manteniendo como parte de su existencia y su ser. De modo tal que estas pedagogías se fundan en las memorias colectivas de los ancestros que con sus enseñanzas, palabras y acciones dieron rumbo a una existencia digna, complementaria y relacional de seres (vivos y muertos, humanos y no humano) con y como parte de la Madre Tierra. A la vez que animan el 
pensar y el sentir desde y con genealogías, racionalidades, conocimientos, prácticas y sistemas civilizatorios y de vivir distintos al occidental. Se trata de pedagogías que incitan posibilidades de estar, ser, sentir, existir, hacer, pensar, mirar, escuchar y saber. Además las luchas sociales son escenarios pedagógicos donde se ubican estrategias, prácticas y metodologías (en tanto pedagogías) de rebeldía que los diferentes pueblos emplearon para resistir, transgredir y subvertir la dominación, para seguir siendo, sintiendo, haciendo, pensando y viviendo a pesar del poder colonial Walsh, $(2013 ; 25)$.

La instalación de las perspectivas descoloniales en la educación se caracterizan por su discontinuidad, su parcialidad y por su ubicación entre las fronteras del ser y del no ser, de lo aceptado y lo rechazado, de lo instituído y lo instituyente. Aluden a un universo opaco, difuso y espectral, que rompe con "el" relato celebratorio de la modernidad y del eurocentrismo universalizado. Se inscriben "casa adentro" y "casa afuera" del saber científico y conforman pedagogías inconclusas y abiertas, que al recuperar cosmologías interrumpidas que discuten sobre el carácter normativo, acabado, mediado y colonizado de la educación. A su vez comprometen el cuestionamiento de las lógicas que desde su campo controlan silenciosamente los cuerpos y las conciencias y exigen una vigilancia atenta y aguda para advertir las "grietas" (Walsh, 2014) o espacios de libertad que son posibles de generar en su interior. Es por ello que componen una apuesta en nuestro "vecindario", que promueve preguntas respecto de los conocimientos que validamos y las lógicas con las que los legitimanos, así como la intención de custodiar saberes de otro modo despreciados. Específicamente, estas pedagogías se ocupan de los procesos de distribución y acceso de los conocimientos, así como de los procesos de intervención social insurgentes que ejercen la contestatación, sub-versión y re-institución de las narrativas que se dicen de sí Porta y Yedaide, (2017).

Entonces las pedagogías descoloniales, tal como las significamos en este acto enunciativo, comparten la vocación por el agenciamiento epistémico-político, la exposición de las condiciones de opresión y la complicidad de las instituciones sociales en la perpetuación de la colonialidad del poder. Se extienden, sin embargo, en un movimiento que es en realidad un regreso a las historias y cosmogonías interrumpidas mientras aventuran nuevos horizontes para la vida humana. Las pedagogías descoloniales ponen nombre a las marcas de la colonialidad y desnudan un modo específico, preciso y próximo de poder en la historia. Estas pedagogías permiten advertir los modos en que la empresa científica se ha servido de la legitimidad (auto-arrogada) para asumir potestad 
sobre los modos de decir al otro Ramallo y Yedaide, (2016).

Por lo tanto prometen debilitar cada vez más la pretensión unívoca de "el" relato, re-fundándolo y haciéndolo estallar en micro-relatos con sentido local y clivaje territorial. Al servicio de sus gentes, recobran el derecho de nombrarse a sí mismos y decidir cómo contar sus historias como una reparación histórica ineludible. A partir de ello en nuestra comunidad local se habilitó discusión sobre las representaciones culturales de las otredades subalternas, migrantes, híbridas y fronterizas, desde las pertenencias étnicas, raciales y de géneros en la construcción de subjetividades individuales y otras colectivas. Especialmente en este texto revisamos el relato existente sobre el bachillerato argentino de la primera mitad del siglo XX, tensionando su narrativa colonial y reconociendo otros hilos de significación capaces de imaginar otros sentidos en la educación del siglo XXI.

\section{El bachillerato argentino entre la nostalgia y la utopía}

ormalmente "el" relato del bachillerato argentino en la primera
mitad del siglo XX celebra la modernidad y su progreso occidental
y suele destacar la importancia simbólica en la composición de la nación. Nuestra investigación sobre sus modos de narrarlo se planteó a partir de reconocer transgresiones a la historia canónica de esta formación, desde una narrativa local alimentada por la experiencia del Colegio Nacional Mar del Plata (en adelante CNMdP). Desde ella pudimos identificar -al menos- tres modos de narrar, que si bien se superponen son factibles de establecer una taxonomía.

Uno de ellos responde a los rasgos fundacionales de los colegios nacionales, en la necesidad de legitimar estas instituciones y celebrar la modernidad en el entonces recientemente delimitado territorio argentino. Sus características se enmarcan en la reproducción del discurso oficial, en una apología a la obra fundacional del presidente Bartolomé Mitre. Aquí se ubican no solo las historias institucionales y las escrituras homenajes sino también algunos de los documentos del Estado Nacional (muchos de ellos contemporáneos) que celebran la tarea civilizatoria, nacionalista y elitista desarrollada por estas agencias estatales.

Otras interpretaciones sobre esta formación podrían establecerse a partir de los trabajos clásicos de la historia de la educación en Argentina, como las iniciáticas y fecundas investigaciones desarrolladas por Juan Carlos Tedesco, 
2 Nos referimos a modo de ejemplo a los textos: Puiggrós, A (1991) Sociedad civil y Estado. En los orígenes del sistema educativo argentino. Buenos Aires, Galerna; Tedesco, J (1994) Educación y sociedad en la Argentina (1880-1900). Buenos Aires, CEAL; Dussel, I (1997). Curriclum, humanismo y democracia en la enseñanza media (1863-1920). Buenos Aires, Eudeba.
Adriana Puiggrós o Inés Dussel. ${ }^{2}$ El rasgo común de estas lecturas -tal vez por sus pretensiones de generalización- es una mirada "desde arriba" en la que se suelen reproducir lugares comunes, como los de definir a los currículum y las prácticas de formación como enciclopedistas y antiexperimentales o delimitar como pertenecientes a élites o grupos tradicionales a sus estudiantes. Por otra parte desde las historias locales, la diferencia cultural y las variadas modernidades operadas en el territorio argentino, podemos reconocer otra lectura. Una tercera interpretación recae en la diversidad de los discursos en relación al bachillerato argentino y en las diferentes prácticas que envuelven sus historias. La variabilidad local, la aparición de sujetos silenciados y la emergencia de un paisaje propio son modos emergentes.

Entre estas diferentes maneras de relatar -en diálogo con esta tercer posiciónintentamos ir más allá de la naturalización del relato oficial de la modernidad y re-instituir otras historias, pequeñas y opacas. Pues recogimos identidades, prácticas y experiencias de diferentes sujetos comúnmente olvidados, desde variaciones locales, experiencias personales y recuerdos en común que no olvidan su lugar de enunciación aunque sí su pretensión de generalización. Lo que plantea una ruptura con la historia de la educación atenta a la consolidación del sistema educativo, celebrando su progreso y su excluyente modernidad. En la perspectiva enunciada por Torres Santomé (1992) recordamos que la historia de la educación desde que se generaliza a toda la población puede ser leída también en sus efectos como la historia de la institucionalización y de la legitimación del fracaso escolar de los grupos sociales desfavorecidos. En el problematizar del ingenuo y agresivo discurso que insiste explícitamente, una y otra vez, que a partir de la educación conseguimos una sociedad más igualitaria, sin preguntarnos cuál es nuestro lugar allí y que desigualdades potenciamos Torres Santomé, (1992; 33).

De este modo sobre el relato conocido del bachillerato identificamos algunas perturbaciones que tensionan y provocan hallazgos para comenzar a problematizar la manera en la que estamos relatando las historias de la educación. En un primer aspecto al indagar la propia fundación del CNMdP lejos de ser una instancia de consagración y expansión del Estado nacional argentino, reconocimos una historia conflictiva entre diferentes grupos locales intentando llevar adelante un proyecto propio y la dirigencia central monopolizante del Estado nacional. Vanguardistas y oficialistas se enfrentaron entre 1914 y 1919 para la creación de esta institución, que demoró en su concreción a raíz de las demandas de un colegio alternativo y vinculado 
al paisaje local. Pese a la derrota aparente de los primeros, el proyecto fundacional rechazado continuó operando en la historia institucional y marcó importantes singularidades locales, como el doble ciclo lectivo (con aulas para los estudiantes en el verano) y las enseñanzas alternativas vinculadas con la naturaleza marítima de la ciudad.

De la misma manera al estudiar a los profesores y sus prácticas -a través de las voces de estudiantes o de los registros de clases y trabajos en las aulas conservados en el archivo del colegio analizado- perturbamos la lectura enciclopedista y antiexperimental, que a decir de algunos especialistas caracterizó la enseñanza del bachillerato. Estas otras enseñanzas remarcaron la experimentación pedagógica y otras propuestas de formación ocultadas de los grandes relatos. Los rastros de pequeñas historias ilustran por ejemplo diferentes casos, como los paseos por la ciudad en las clases de biología que Alejandro Bergalli dirigió, el Gabinete de Psicología Experimental que Mauricio Gueventer creó en el año 1925, las lecciones de las grandes obras de la literatura clásica "universal" frente al mar y a otros escenarios de la "naturaleza" que caracterizaron las clases de Gaspar Martin, o las vanguardistas lecciones de música entre la espuma y la sal de Ezequiel Calleja.

También reconocimos otros sujetos en esta formación. Esta investigación reconoció a otros estudiantes e intentamos demostrar que el colegio nacional (una institución fuertemente definida para la formación de las futuras élites y de los sectores privilegiados) lejos de reproducir los círculos de los grupos sociales acomodados fue el marco y el espacio en donde un grupo de mujeres, "gringos" e hijos de inmigrantes de variados orígenes sociales se convirtieron en bachilleres. ${ }^{3}$ Nuestro argumento es que si bien el bachillerato se caracterizó por representar una enseñanza "tradicional", "selectiva" y "elitista", en la práctica este colegio nacional actuó como un espacio abierto y permeable al cual accedieron estudiantes de diferentes lugares en la escala social (o al menos de sectores sociales más amplios que los reconocidos por los discursos de la época y por lo que enuncian los estudios realizados al respecto). Entre ellos la formación en el bachillerato marplantense fue protagonizada por mujeres (que representaron un tercio del alumnado) y "gringos" e hijos de inmigrantes (cuya cifra superó las dos terceras partes).

Asimismo el análisis de los expedientes de los estudiantes y una serie de entrevistas permitió identificar empíricamente a los alumnos del CNMdP y caracterizar sus diversas trayectorias escolares que dada su heterogeneidad-
3 El concepto gringo si bien hace referencia a ser extranjeros (sobre todo en la utilización de una lengua no inteligible y costumbres diversas) presenta diferentes usos según el contexto temporal y espacial. 
clasificamos a los más numerosos en diferentes grupos: "exitosos" (los graduados), "transitorios" (alumnos temporales no graduados) y "veraneantes" (propios de la institución, rendían sus exámenes durante el verano y luego volvían a sus respectivos colegios). Además estos otros estudiantes son tales en varios sentidos, un cuarto aspecto refiere a diversas experiencias y usos del bachillerato. Pues, el pertencer al CNMdP habilitó puertas sociales independientemente del título de Bachiller, en algunas ocasiones el "tercer año aprobado" o incluso solo el primero era de por sí un recorrido con espesor propio y reconocido como tal. Más aún en una ciudad cuyo colegio nacional cumplió una función de mediación cultural en un espacio periférico del reciente Estado argentino.

Finalmente las experiencias de estos estudiantes revelan una metamorfosis en la construcción de sujetos con notabilidad, relevancia y visibilidad pública, las llamadas "personas de bien". En ese trayecto reconocemos que se formó un tipo de ciudadano que consolidó el ideal del colegio nacional "civilizador", por lo que también la vida en el colegio nacional estuvo atravesada por el blanqueamiento social en las expectativas de convertir a sus estudiantes en notables ciudadanos -moralistas, disciplinados, racionalizados, cristianos, heterosexuales y padres de familia-, diferenciándose de los otros por su "cultura" y "éxito". El relato oficial de bachillerato y las voces de algunos de los que formaron parte de esta experiencia fundó su gloria en la creación de "hombres de bien", que glorificaban con sus vidas sus propios relatos y los del colegio nacional. En efecto la experiencia del bachillerato fue abrazada con tanta admiración, que los nuevos tiempos solo inspiraron un sentimiento y un pensamiento nostálgico respecto de la educación. El mismo que creemos caracterizó (y aún caracteriza) a los relatos sobre el bachillerato, tanto en sus reseñas institucionales como en la producción académica.

En tal sentido nuestro relato está ubicado en un combate con esas lecturas nostálgicas que respaldan posicionamientos y modos de comprender la educación en nuestro presente. En consecuencia creemos que merecemos otro relato, uno en el que prevalezca la posibilidad y el optimismo por sobre la melancolía, en donde los otros del pasado -como nosotros en el presentepodamos decidir, actuar, ser y existir libremente. En tal sentido recuperamos la idea de una narración utópica, aquella que vigoriza el relato fosilizado, lo abre y lo ramifica para dar lugar a nuevas historias. Al respecto Cristina Nosei (2010) al indagar el impacto de la obligatoriedad de la enseñanza secundaria en sus investigaciones sobre el fracaso escolar, identificó dos tipos de enunciadores 
los relatores nostálgicos y los narradores utópicos. Sustentándose en la lectura de Gilles Deleuze y atenta a la voz de los docentes entrevistados esta pedagoga planteó que el relator repite pasivamente siempre la misma historia -tal como un copista refleja una obra que le es ajena- mientras que el narrador cambia, construye y reconstruye la historia de la que se siente parte activa y responsable.

A partir de ello proponemos un tránsito de enunciación de relatores nostálgicos a narradores utópicos, con la intención de desnaturalizar los relatos que nos rodean y recordar que en la educación se produjeron otras marcas. Y que es necesario más allá de lo registrado, perturbar al texto hegemónico en la incesante búsqueda de un "equilibrio de voces" Bidaseca, (2010). A lo que agregaríamos aún con más fuerza que el recoger de historias olvidadas reconstruye posicionamientos invisibilizados para desestabilizar las teoría de lo obvio, en la comprensión de mitos y la representación de una historia ocultada el presente.

\section{(In)conclusiones: Gestos descoloniales en la Historia de la Educación}

T as perspectivas descoloniales en educación proponen un ejercicio constante y siempre parcial de desnaturalizar la dolorosa colonialidad que nos atraviesa. El recuperar del derecho a contar nuestras propias historias, alimentadas por cosmologías interrumpidas de las gentes profundiza una pregunta pocas veces formulada sobre la composición de nuestras historias y sus sentidos en nuestro cotidiano. De hecho pocas veces percibimos "el" relato colonizado de la educación que continuamos habitando. Las pequeñas historias que recogimos implican un desprendimiento de las grandes narrativas de estos pasados y remarcan transgresiones desde la diferencia cultural y las variaciones locales. Estas pequeñas historias, de otra formación y otros estudiantes, discuten la gloria civilizatoria y posibilitan refundar los relatos existentes con las resistencias de nuestra propia experiencia de la modernidad.

En tal sentido re-instituir otras historias -con otros sentidos- que se pregunten y se construyan en relación a las gentes, potencian espacios para provocar transformaciones en el modo de hacer, pensar y sentir la educación. Ello no implica olvidar su fragilidad, incertidumbre, inseguridad, escurridez y arriesgo, sino que por el contrario convoca a rescatar voces y experiencias que sedimentan una pedagogía descolonial no excluyente y situada en la inmediatez. En esa inmediatez reconocemos que una pedagogía descolonial 
no es de manual, normativa, recetaria, directiva, sino que se autoconstituye a partir de desprendimientos. Estas pedagogías son indisociables de la experiencia humana y se encuentran sobre todo en los saberes cotidianos que muchas veces despreciamos.

En un pensar desde y con el sur Boaventura de Souza Santos (2006) abogó por un cambio civilizatorio que necesita pasar por un cambio epistemológico, renovando las teorías de la emancipación y acompañando la modificación de las formas de vida occidentales. Para ello es necesario involucrarnos en cuanto sujetos con la utopía del buen vivir, frente a los "epistemicidios" y los modos de producción de ausencias propios de la racionalidad moderna occidental. Aquella se funda en una "monocultura del tiempo lineal", en una idea sobre la historia sustentada en nociones como dirección, desarrollo, evolución, progreso y modernización. En la que se constituye una temporalidad que opera distribuyendo y asignando lugares. Sin embargo desde la "ecología de los saberes" podríamos decir que existen otros tiempos diferentes al lineal y ello implica dar lugar a que cada forma de sociabilidad tenga su propia temporalidad. Por tanto las temporalidades expanden, complementan y enriquecen a la linealidad enunciada como universal. En su crítica el sociólogo portugués planteó que la razón en su manifestación metonímica restringe el presente, mientras que una razón proléptica amplía en futuro. Por tanto propone una inversión utópica: ampliar el presente y constreñir el futuro.

Sumado a ello podríamos decir que lo importante no es ver cómo el conocimiento representa lo real, sino conocer lo que un determinado conocimiento produce en la realidad. En la intervención de lo real, en un paso de la reproducción a la producción. De modo que es importante reconocer cuál es el tipo de intervención que el saber produce con los relatos del pasado en la educación. Y desplazar la mirada a la acción habilita gestar otras formas de articulación entre saberes y urgencias, capaz de intervenir en la matriz clásica de la pedagogía alternando tiempos, sociabilidades y espacios. Es entonces que las pedagogías descoloniales se nos presenta como locus matricial para pensar lo educativo en términos políticos, tanto por la re-inscripción del sujeto como actor y autor en las esferas públicas, como por el reconocimiento de que el atravesamiento del poder en la educación -omnipresente, ubicuo y performativo- exige una perspectiva histórica para su comprensión y transformación. La apuesta de estas pedagogías registra en la actualidad un movimiento contundente hacia la ampliación de lo educativo más allá -e incluso por fuera y a espaldas- de las escuelas para 
advertir y volver objeto de escrutinio al resto de las agencias de producción cultural que pugnan por re-instituir sentidos y monopolizar las tramas semióticas en el tejido social. Asimismo se ocupan de la construcción de la hegemonía en el territorio discursivo y de las resistencias e irreverencias de colectivos sociales auto-organizados, decididos a participar de la arena pública en que se asumen decisiones que los afectan Ramallo y Yedaide, (2016). Por tanto las pedagogías descoloniales pueden ser comprendidas como prácticas de autorización discursiva que proporcionan indicios sociohistóricos potentes, a la vez que inauguran posibilidades de restituir modos de ser y conocer formas de agenciamiento cívico y epistémico-político Porta y Yedaide, (2017).

La Historia de la Educación desde las perspectivas descolonial provocan un ejercicio de visualización de nuevos horizontes que actúan como gestos. Un gesto descolonial funciona como una advertencia y como una anticipación de lo por-venir que solo tiene sentido en nuestra inmediatez, en la afectación sensible de nuestro cotidiano y de nuestro vencidario Porta y Yedaide, (2017). La idea de gesto ante todo resalta su parcialidad, fragmentación y pequeñez. Dada la imposibilidad de una colonialidad cero y de una transgreción total, un gesto se proyecta como lo que podemos hacer cuando dejamos de preferir el orden vigente $y$, al menos un poco, nos alejamos de las pretensiones de la certeza científica y civilizatoria.

En el cuestionar de la autoridad de los relatos oficiales el gesto descolonial apuesta a profundizar la educación. En tanto la educación no queda expresada en descripciones de hechos ni en interpretaciones de lo que ocurre, lo educativo apela a algo que no está en lo que pasa, sino en un modo de preguntar(nos) por eso que pasa y que remite a su sentido, su deseabilidad, su posibilidad Contreras Domingo, $(2016 ; 40)$. A su vez reconocer tal sentido implica una forma especial de mirar a la educación, no como un objeto que se estudia desde fuera sino como una experiencia que se mira desde adentro. Más que tocar lo delicado, sutil y misterioso de la educación, de lo que se trata es de dejarse tocar. Contando historias, exponiendo situaciones vividas, también estamos incrustándonos en ellas. Lo importante de esta historia no se reduce a satisfacer nuestra curiosidad por lo que pasó, lo que importa de ella es lo que hace con nosotros y lo que nosotros hacemos con ella Contreras, $(2016 ; 42)$.

Finalmente nos interesa recuperar que en esta lucha por la representación, los sujetos podríamos intervenir -especialmente aquellos que resistimos a 
convertirnos en objeto de un relato-. Por tanto se torna urgente asumir el agenciamiento político y narrar, en sentido de re-instituir, para el desaprendizaje y la emancipación de nuestras conciencias. Para ello aseveramos que cualquiera sea el relato del pasado, este debe ser puesto al servicio de las gentes para que recuperemos la autonomía que nos permita tejer los hilos de nuestra propias vidas (Segato, 2015). Estas historias nos recuerdan que el relato instituido no es el único posible, sino que podrían existir otros. Delimitando estas intenciones, quedamos siempre a la escucha de otros modos posibles, en este ampliar de horizontes para habitar una pedagogía descolonial, capaz de enunciar desde otras memoria el cuidado de la libertad y la dignidad humana. Pedagogías desde nuestra inmediatez, que parten desde nosotros a partir de diferentes modos de conocernos.

\section{REFERENCIAS BIBLIOGRÁFICAS}

BIDASECA, K. (2010). Perturbando el texto colonial. Los estudios (pos)coloniales en América Latina. Buenos Aires: SB.

CASTRO Gómez, S. (2005). La poscolonialidad explicada a los niños. Popayán (Colombia), Editorial Universidad del Cauca.

CASTRO Gómez, S. y Grosfoguel, D. (2007). El giro decolonial. Reflexiones para una diversidad epistémica más allá del capitalismo global. Bogotá: Pontificia Universidad Javeriana, Universidad Central, Siglo del Hombre Editores.

CONTRERAS, D. (2016) "Profundizar narrativamente la educación" En: De Souza, EC (Org). (Auto)biografías e documentação narrativa: redes de pesquisa e formação. Salvador, EUDEBA.

MIGNOLO, Walter (2007). "El pensamiento descolonial, desprendimientos y apertura: un manifestó". En: Castro-Gómez, Santiago y Ramón Grosfoguel (editores). El giro decolonial. Reflexiones para una diversidad epistémica más allá del capitalismo global. Bogotá: Pontificia Universidad Javeriana, Universidad Central, Siglo del Hombre Editores

NOSEI, C. (2010) "La formación de profesores en el nivel superior: la construcción y deconstrucción de significados en referencia a la acción de enseñar". En: III Jornadas Nacionales sobre Pedagogía de la Formación del Profesorado. Miramar, noviembre 2010.

PORTA, L y Yedaide, M (2017). Pedagogía(s) vital(es). Cartografías del pensamiento y gestos éticopolíticos en perspectiva descolonial. Mar del Plata: EUDEM.

RAMALLO, F y Yedaide, M (2016). "Entre historia, historias y relatos: El desafío de la representación de lo pedagógico en la formación docente". En: III Congreso de Estudios Poscoloniales y IV Jornadas de Feminismo Poscolonial Buenos Aires, Diciembre de 2016. 
RAMALlO, F. y Porta, L. (2017) “(Re) Fundar un relato desde la memoria escolar: Narrativas y prácticas en la historia del bachillerato argentino". En: Journal for Educators, Teachers and Trainers (JETT) Vol. 8 (1), (ISSN 1989 - 9572). Pp-pp 35 - 46. Consulta On Line: http://jett. labosfor.com/index.php/jett/article/viewFile/271/307

RAMALLO, F. (2017). "El bachillerato como experiencia: Un abordaje biográfico narrativo desde el Colegio Nacional de Mar del Plata (1914-1940". Tesis de Doctorado en Humanidades y Artes. Universidad Nacional de Rosario.

SEGATO, R. (2015). La crítica de la colonialidad en ocho ensayos. Y una antropología por demanda. Buenos Aires: Prometeo Libros.

SOUZA Santos, B (2006). Renovar la teoría crítica y reinventar la emancipación social. (Encuentros en Buenos Aires). Buenos Aires: CLACSO Argentina.

TORRES Santomé, J. (1992). Currículum oculto. Madrid, Morata.

WALSH, C. (2013) Pedagogías Descoloniales: Prácticas insurgentes de resistir, (re) existir y (re) vivir. Quito, Serie Pensamiento descolonial.

WALSH, C. (2014) Pedagogías decoloniales caminando y preguntando: notas a Paulo Freire desde Abya Yala. Revista Entramados. Educación y Sociedad. UNMdP -Universidad La Gran Colombia. No. 1, Año 1 Consulta On line:

http://fh.mdp.edu.ar/revistas/index.php/entramados/article/view/1075/1118.

YEDAIDE, MM. Álvarez , Z y Porta, L (2015) La investigación narrativa como moción epistémico-política. Revista Científica Guillermo de Ockham, 13 (1), 27-35. 